\title{
DCE-MRI and IVIM-MRI of rabbit Vx2 tumors treated with MR-HIFU-induced mild hyperthermia
}

Mie K. Lam*, Chris Oerlemans, Martijn Froeling, Roel Deckers, Angelique D. Barten-Van Rijbroek, Max A. Viergever, Chrit T. W. Moonen, Clemens Bos and Lambertus W. Bartels

\begin{abstract}
Background: The purpose of this study is to investigate whether changes could be detected in dynamic contrast-enhanced (DCE) and intra-voxel incoherent motion (IVIM) MR parameters upon MR-guided high-intensity focused ultrasound (MR-HIFU)-induced hyperthermia in a rabbit Vx2 tumor model.

Methods: Five Vx2 tumor-bearing New Zealand white rabbits were treated with hyperthermia using a clinical MR-HIFU system. Data were acquired before and after hyperthermia. For the DCE analysis, the extended Tofts model was used. For the IVIM analysis, a Bayesian approach was used. Maps were reconstructed of the DCE parameters $\left(K^{\text {trans }}, k_{\mathrm{e} p}\right.$, and $\left.v_{p}\right)$ and IVIM parameters $\left(D_{t}, f_{p}\right.$, and $\left.D_{p}\right)$. Individual parameter histograms and two-dimensional cross-correlation histograms were constructed to analyze changes in the parameters after hyperthermia. Changes in median values were tested for statistical significance with the Mann-Whitney $U$ test.

Results: The MR temperature measurements confirmed that mild hyperthermia (40 to $42{ }^{\circ} \mathrm{C}$ ) was successfully achieved in all rabbits. One rabbit died during treatment and was excluded from the analysis. In the remaining four rabbits, an increase in $D_{t}$ was observed. In three rabbits, an increase in $K^{\text {trans }}$ was observed, while in the other rabbits, all three DCE parameter values decreased. Mixed changes were seen for $v_{p}$ and $f_{p}$.

Conclusions: Changes in DCE and IVIM parameters were detected after hyperthermia and were variable between the rabbits. DCE- and IVIM-MRI may be promising tools to assess tumor responses to hyperthermia. Further research in a larger number of subjects is necessary in order to assess their value for treatment response monitoring.
\end{abstract}

Keywords: Dynamic contrast-enhanced MRI, Intra-voxel incoherent motion MRI, Hyperthermia, MR-HIFU

\section{Background}

While MR-guided high-intensity focused ultrasound (MRHIFU) has been used for ablative treatments, the technology also shows promise for the induction of local mild hyperthermia. One of the physiological effects is the improvement of tumor oxygenation, which has been reported to increase the effectiveness of radiotherapy [1,2]. Other physiological effects are changes in blood flow and vascular permeability, which could enhance local drug delivery of chemotherapeutic agents [3, 4]. Information about tumor physiology is valuable since it is an important determinant of treatment outcomes [5, 6]. Physiological

\footnotetext{
* Correspondence: M.K.Lam-4@umcutrecht.nl Imaging Division, University Medical Center Utrecht, Utrecht, The Netherlands
}

responses of tumors to hyperthermia have been extensively investigated in rodent models using invasive measurement methods [7-13]. Tumors are more sensitive to heating and stasis of the blood flow occurs at lower hyperthermic temperatures as compared with normal tissue $[7,8]$. Changes in regional blood flow and permeability after hyperthermia were reported to show both interand intra-tumoral variations [7, 13]. The underlying mechanisms are complex and depend on several factors, e.g., the chemical microenvironment and tumor architecture [7], which make it difficult to predict tumor responses to hyperthermia. Noninvasive methods to map physiological changes would therefore be useful for investigating tumor responses to hyperthermia $[14,15]$. 
Dynamic contrast-enhanced (DCE) magnetic resonance imaging (MRI) is a method widely used to map quantitative perfusion and permeability parameters $[16,17]$. Dynamic $T_{1}$-maps are acquired before, during, and after the injection of a paramagnetic contrast agent bolus. Contrast concentration-time curves are derived from the dynamic $T_{1}$ maps, and perfusion parameters can be extracted by fitting a physiological model, such as the Tofts model [18, 19]. Many studies have reported on the potential of DCE-MRI as a prediction tool for treatment response of tumors to radiotherapy $[20,21]$, neo-adjuvant chemotherapy [22-24], and neo-adjuvant chemoradiation [25-27].

Intra-voxel incoherent motion (IVIM) MRI is a method that allows measurements of perfusion-related parameters from diffusion-weighted MR data. The nonBrownian motion of blood flowing through pseudo randomly organized capillary networks is considered as incoherent motion. This generates a "pseudo diffusion" effect and contributes to the diffusion-weighted MR signal. By using a bi-exponential description of the MR signal, parameters related to the vascularity can be extracted [28]. Although these parameters should be interpreted carefully $[29,30]$, the vascular contribution to measured IVIM parameters has recently been verified in healthy volunteers [31]. Recent studies showed promising results using IVIM for the characterization of various diseases of different organs, for example, cirrhotic liver [32], pancreatic carcinoma [33], locally advanced breast cancer [34], salivary gland tumors [35], brain pathologies [36], and renal tumors [37].

In this study, we investigated the potential of DCEand IVIM-MRI to detect changes induced by hyperthermia in rabbits with Vx2 tumors, using the extended Tofts DCE-MRI model and a Bayesian approach for IVIM analysis. To this end, a clinical MR-HIFU system was used, which allows of noninvasive local hyperthermia in small animals [38-42].

\section{Methods}

\section{Animal handling and $\mathbf{V} \times \mathbf{2}$ tumors}

All experiments were approved by the University Animal Experiments Committee and were performed in agreement with The Netherlands Experiments on Animals Act (1977) and the European Convention guidelines (86/ $609 /$ EC). Five female New Zealand white rabbits (2.5$3.5 \mathrm{~kg}$, Charles River, France) were housed in pairs and were provided with food and ad libitum water. Vx2 tumor pieces were retrieved from donor rabbits and implanted intramuscularly in the left hind limb. The tumors grew to a volume of $10 \mathrm{~cm}^{3}$ in about 3 weeks, after which the imaging experiment was performed.

The rabbits were initially anesthetized with a subcutaneous injection of dexmedetomidine $(0.125 \mathrm{mg} / \mathrm{kg}$,
Dexdomitor, Jansen Pharmaceutica N.V., Beerse, The Netherlands) and ketamine (15 mg/kg, Narketan 10, Vétoquinol S.A., Lure Cedex, France). The tumorbearing hind limb was shaved, depilated, and covered with ultrasound gel for acoustic coupling. To prevent undesired leg movement during HIFU exposure, a sciatic nerve block was performed (bupivacaine $2 \mathrm{mg} / \mathrm{kg}$ ). Then, a fluoroptic temperature probe (Luxtron, Santa Clara, CA) was placed in the muscle tissue adjacent to the tumor to allow measurements of the baseline temperature as is used for the relative MR thermometry.

A catheter (Abbocath ${ }^{-}-\mathrm{T}$ I.V. Catheter $22 \mathrm{~g} \times 1.25$ ", Hospira Inc., Lake Forest, IL) was placed in the marginal ear vein and was connected to a Luer-lock 3-way valve, providing two inputs. One input was used for the intravenous maintenance anesthesia (one third of the initial dose per hour), which was provided using a pressure pump system up to $5 \mathrm{~h}$ after the initiation of anesthesia. The other input was available for intravenous injection of the MR contrast agent gadobutrol (GadoVist, $0.1 \mathrm{mmol} / \mathrm{kg}$, Gadovist, Bayer Pharma). After the experiment, the rabbits were terminated with an overdose of sodium pentobarbital injected intravenously.

\section{Experimental setup}

A clinical MR-HIFU therapy system was used (Sonalleve V2, Philips Healthcare, Vantaa, Finland) integrated into a clinical 1.5T MRI scanner (Achieva, Philips Healthcare, Best, The Netherlands). An in-house developed animal holder as previously described by Wijlemans et al. [43] was used, which consisted of an open polymethylmethacrylate tank with an acoustic window in the bottom. A schematic overview of the setup is shown in Fig. 1a. The tank was filled with heated water up to the tumorbearing leg, to enable acoustic coupling and to achieve a baseline temperature similar to human body temperature $\left(37{ }^{\circ} \mathrm{C}\right)$. A heating blanket was placed on top of the rabbit to keep the baseline temperature stable.

\section{MR imaging}

A four-channel RF receiver coil integrated into the MRHIFU tabletop was used, together with a flat 16-channel array coil, which was placed on top of the heating blanket (Fig. 1a).

To plan the position of the HIFU focus, an anatomical $\mathrm{T}_{2}$-weighted $3 \mathrm{D}$ turbo spin-echo (TSE) sequence was used with the following scan parameter settings: echo time $(\mathrm{TE})=254 \mathrm{~ms}$, repetition time $(\mathrm{TR})=$ $1000 \mathrm{~ms}$, flip angle $(\mathrm{FA})=90^{\circ}$, TSE factor $=21$, acquisition bandwidth $(\mathrm{BW})=245.5 \mathrm{~Hz}$, voxel size $=2 \times 2 \times$ $2 \mathrm{~mm}^{3}$, field of view $(\mathrm{FOV})=250 \times 250 \times 126 \mathrm{~mm}^{3}$, number of signal averages $(\mathrm{NSA})=2$. Figure $1 \mathrm{~b}, \mathrm{c}$ shows examples of treatment planning on reconstructed sagittal and coronal images. 

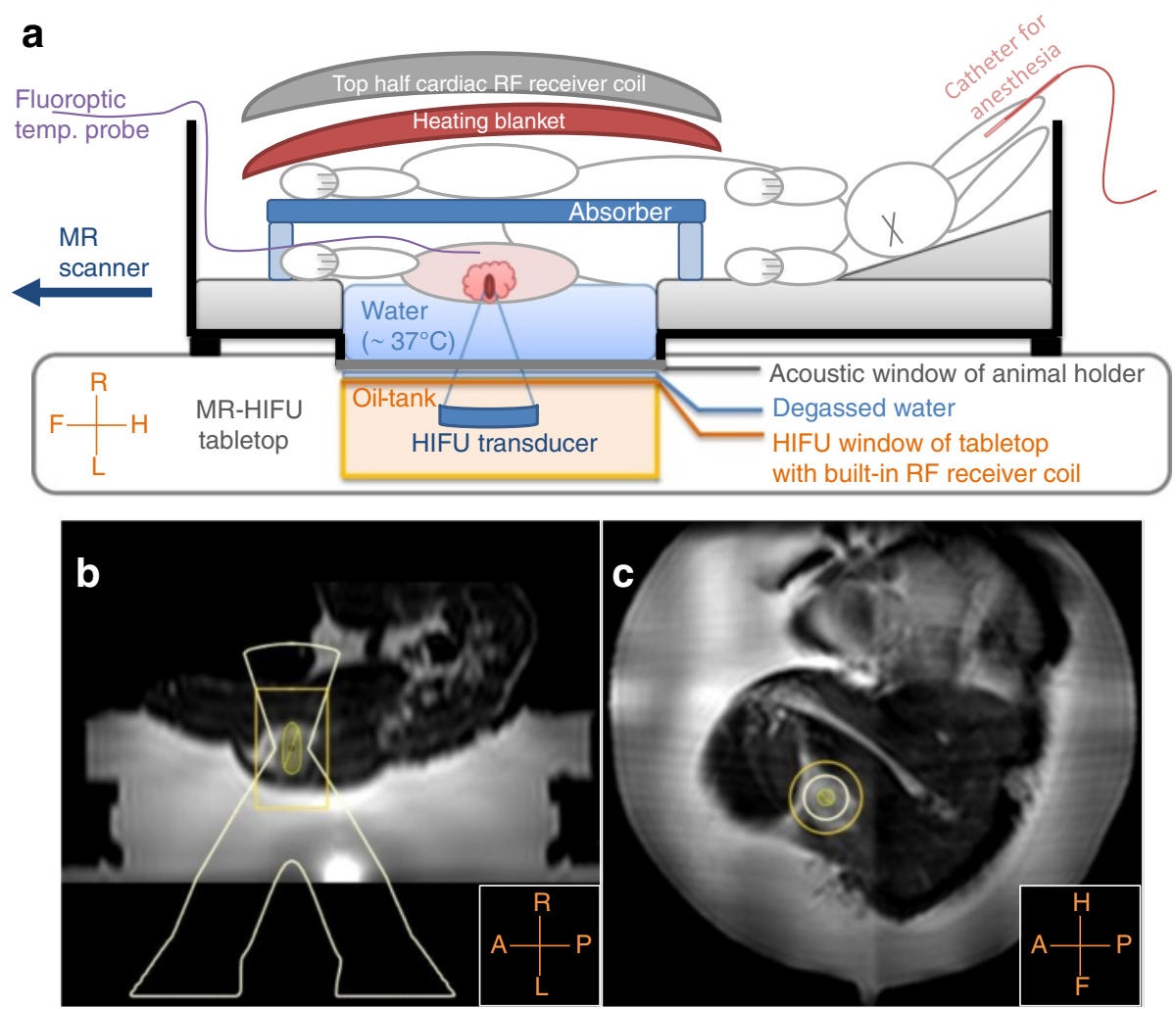

Fig. 1 Experimental setup. A schematic overview of the experimental setup is shown in (a). The animal holder was placed with its acoustic window above the HIFU window; degassed water was used for acoustic coupling. The shaved tumor-bearing leg was positioned above the acoustic window, and a fluoroptic temperature probe was inserted in the tumor-bearing leg, in the far-field of the HIFU beam. The tank was filled with warm water $\left(\sim 37^{\circ} \mathrm{C}\right)$ up to the tumor-bearing leg, and an absorber was placed between the legs. On top of the rabbit, a heating blanket and a flat 16-channel array coil was placed. In $(\mathbf{b}, \mathbf{c})$, examples of the treatment planning are shown on reconstructed sagittal and coronal images of the $\mathrm{T}_{2}$-weighted 3D turbo spin-echo acquisition

The MR thermometry scan used was a multi-slice gradient-echo planar imaging (EPI) pulse sequence with binomial water-selective RF excitation. One stack of three coronal slices and one sagittal slice were acquired, of which the centers were aligned with the HIFU focus. A saturation slab was used to suppress signal from the water tank. The scan parameter settings were as follows: $\mathrm{TE}=20 \mathrm{~ms}, \mathrm{TR}=44 \mathrm{~ms}, \mathrm{FA}=20^{\circ}, \mathrm{BW}=39.5 \mathrm{~Hz}$, pixel size $=2.5 \times 2.5 \mathrm{~mm}^{2}$, slice thickness $=7 \mathrm{~mm}$, FOV $=$ $250 \times 250 \mathrm{~mm}^{2}$, NSA $=2$, EPI factor $=11$, and dynamic scan duration $=3.9 \mathrm{~s}$. Temperatures changes were calculated on the fly using the proton resonance frequency shift method [44, 45] and added to the baseline temperature measured with the fluoroptic probe in order to reconstruct temperature images.

The baseline $T_{1}$ map, required for DCE-MRI analyses, was obtained from variable flip angle (VFA) images acquired prior to contrast agent injection. The DCE-MR images and VFA images were acquired before and after hyperthermia and were orientated parallel to the tumorbearing leg. The VFA images were acquired with a 3D spoiled gradient-echo: $\mathrm{TE}=1.4 \mathrm{~ms}, \mathrm{TR}=5 \mathrm{~ms}, \mathrm{FA}=5^{\circ}$, $10^{\circ}$, and $15^{\circ}, \quad \mathrm{BW}=192 \mathrm{~Hz}$, voxel size $=1.2 \times 1.5 \times$ $2 \mathrm{~mm}^{3}$, FOV $=300 \times 150 \times 40 \mathrm{~mm}^{2}$, and NSA $=2$. For the DCE-MR images, the same scan sequence was used with dynamic keyhole settings [46], using the last scan for the high spatial frequency data, keyhole percentage $=$ $25 \%$, keyhole measurements $=2$, dynamic reference scan duration $=13.1 \mathrm{~s}$, dynamic keyhole scan duration $=3.3 \mathrm{~s}$, total scan duration $=5 \mathrm{~min}, 47 \mathrm{~s}$, and FA $=15^{\circ}$. MR contrast agent was injected between 15 and $20 \mathrm{~s}$ after starting the dynamic DCE scan. The DCE-MRI scan was acquired on average $10 \mathrm{~min}$ (range 6.5 to $17.5 \mathrm{~min}$ ) after the end of hyperthermia.

For IVIM-MRI, multi-slice diffusion-weighted singleshot spin-echo EPI images were acquired before and after hyperthermia. The orientation of the slices was parallel to the tumor-bearing leg and $10 b$ values were used. The scan parameter settings were as follows: $\mathrm{TE}=$ $67 \mathrm{~ms}, \mathrm{TR}=2500 \mathrm{~ms}, \mathrm{FA}=90^{\circ}, \mathrm{BW}=15.7 \mathrm{~Hz}$, pixel size $=2 \times 2 \mathrm{~mm}^{2}$, slice thickness $=3 \mathrm{~mm}, \quad \mathrm{FOV}=140 \times$ $179 \mathrm{~mm}^{2}$, number of slices $=12, \mathrm{NSA}=6$, and $b=800$, $600,400,200,150,100,75,50,25,0 \mathrm{~s} / \mathrm{mm}^{2}$. A frequency-selective adiabatic inversion pulse was used 
for fat suppression, with a delay time of $90 \mathrm{~ms}$. The IVIM-MRI scan was acquired on average $35 \mathrm{~min}$ (range 26 to $43 \mathrm{~min}$ ) after the end of hyperthermia.

\section{MR-HIFU-induced mild hyperthermia}

Mild hyperthermia ( 40 to $42{ }^{\circ} \mathrm{C}$ ) was induced locally in all five rabbits using the clinical MR-HIFU therapy system described earlier. Sonications were performed with $60 \mathrm{~W}$ acoustic power at an operating frequency of 1.2 $\mathrm{MHz}$, and the acoustical energy was delivered along concentric circular sub-trajectories of 4 and $8 \mathrm{~mm}$ diameter by electronically steering the focus, the so-called HIFU cell [47]. Mild hyperthermia was achieved by the binary feedback-loop described by Partanen et al. [48], which uses the temperature measurements provided by the MR thermometry. After initial heating to mild hyperthermic temperatures, hyperthermia was maintained by re-sonicating the sub-trajectories using a binary feedback-loop. In this study, the binary feedbackloop was slightly adapted: re-sonication was done with $80 \%$ of the initial acoustical power instead of $50 \%$.

The hyperthermia protocol consisted of three hyperthermia blocks of $10 \mathrm{~min}$, separated by periods of cooling. Each subsequent hyperthermia sonication started when the temperature, measured by the fluoroptic temperature probe, had decreased to the baseline temperature measured prior to heating. A hyperthermia block was considered unsuccessful and was redone after cooling down when the duration of the hyperthermia block was less than half of the intended duration, for example, due to automatic abortion by the system upon detection of large motion.

The measured hyperthermic temperatures by MR thermometry were expressed by the measures $T_{10}, T_{50}$, and $T_{90} . T_{50}$ indicates the median temperature or the temperature that was exceeded by $50 \%$ of the target region. Similarly, $T_{10}$ and $T_{90}$ indicate that the temperature was exceeded by 10 and $90 \%$ of the target region, respectively. These values were calculated over manually selected circular regions of interest (ROI) with a diameter of $10 \mathrm{~mm}$ at the heated area in each slice, slightly larger than the HIFU cell size. Temporal mean values were calculated for the entire hyperthermia duration, i.e., the time period between the start and end of the hyperthermia maintenance phase of the feedback algorithm of each block, for the sagittal slice and the central coronal slice.

\section{Tumor VOls}

For all datasets, a 3D tumor volume of interest (VOI) was selected by manual delineation of the tumor region in each slice. This tumor VOI represents the volume targeted for hyperthermia. The tumor VOIs were used for the comparison of the parameters before and after hyperthermia. In the DCE datasets, the delineation was performed after the bolus passage at the 20th dynamic; in the IVIM datasets, the delineation was performed at $b=0 \mathrm{~s} / \mathrm{mm}^{2}$.

\section{DCE data analysis}

The DCE-MRI analysis was performed in Matlab (2013b, Mathworks, Natick, MA). First, dynamic 3D concentration maps were reconstructed from the DCE data, using the $T_{1}$ baseline maps obtained from the VFA data [49]. Second, arterial input functions (AIFs) were measured in the feeding artery of rabbit 5 in both the pre- and post-hyperthermia data. These representative concentration-time curves were parameterized using a gamma variate function [50]. The blood plasma volume fraction $v_{p}$ has been reported to be a crucial parameter for the assessment of tumor physiological response to hyperthermia and thus should be included in the analysis [14, 15]. Therefore, the extended Tofts DCE model $[18,51]$ was used:

$$
C(t)=K^{\operatorname{trans}} \int_{0}^{t} C_{p}(\tau) e^{k_{\mathrm{ep}}(t-\tau)} d \tau+v_{p} C_{p}(t),
$$

where $K^{\text {trans }}$ is the volume transfer constant between blood plasma and the extracellular extravascular space (EES), $k_{\text {ep }}$ is the rate constant between the EES and the blood plasma, and $C_{p}(\tau)$ is the concentration-time curve in the arterial blood plasma or the AIF. Equation 1 was fitted voxel-wise to the dynamic concentration maps using an iterative nonlinear least squares fit procedure, where the parameterized pre- and post-hyperthermia AIFs were used for the analysis of the pre- and posthyperthermia data, respectively. Maps were reconstructed of $K^{\text {trans }}, k_{\text {ep }}$, and $v_{p}$.

\section{IVIM data analysis}

The IVIM-MRI analysis was performed using the data driven Bayesian modeling method described by Orton et al. [52], which has no user-defined parameters and is therefore robust and reproducible [52]. The method was implemented in Mathematica (7.0, Wolfram Research Inc., Champaign, IL), and the following bi-exponential model was used:

$$
S(b)=S_{0}\left(f_{p} e^{-b \cdot D_{p}}+\left(1-f_{p}\right) e^{-b \cdot D_{t}}\right)
$$

where $D_{t}$ is the true diffusion, $f_{p}$ is the perfusion fraction, and $D_{p}$ is the pseudo diffusion, induced by the vascular components. The Bayesian modeling method makes Gaussian approximations of the IVIM parameter histograms, resulting from least squares fitting of Eq. 2 . 
These approximations are used as prior distributions to push outlier estimates with high uncertainty towards the center of the histogram [52]. To fill the prior distribution appropriately, the muscle surrounding the tumor was included and any water from the tank was excluded. Maps were reconstructed of $D_{t}, f_{p}$, and $D_{p}$.

\section{Detection of changes after hyperthermia}

While the mean of a VOI is an often used metric for the comparison of parameter values, histograms are less arbitrary and capture heterogeneity [6, 14, 37, 53]. Histograms were made for each DCE and IVIM parameter, with ranges of 0 to 5 for $K^{\text {trans }}\left[\mathrm{min}^{-1}\right]$ and $k_{\text {ep }}\left[\mathrm{min}^{-1}\right], 0$ to 1 for $v_{p}$ [fraction] and $f_{p}$ [fraction], 0 to 3 for $D_{t}\left[10^{-3} \mathrm{~mm}^{2} / \mathrm{s}\right.$ ], and 0 to 30 for $D_{p}\left[10^{-3} \mathrm{~mm}^{2} / \mathrm{s}\right]$. All data were distributed in 100 bins, and the bin heights were expressed in percentage of the tumor VOI volume.

For quantitative comparison, we determined the median values of all values inside the mentioned ranges (excluding the outliers). The parameter distributions were expected to be non-normal owing to tumor heterogeneity, and the pre- and post-hyperthermia data were unpaired since the tumor VOIs were delineated individually. Therefore, the Mann-Whitney $U$ test was used, which was also performed in a region of interest in the surrounding muscle to test the significance of the changes in the median values. The region in the surrounding muscle used for the analyses was selected in the central slice through the tumor. The muscle region size was $10 \times 10$ voxels for DCE and $5 \times 5$ voxels for IVIM. The selected muscle region was smaller for IVIM than for DCE, because of the lower resolution and the limited availability of surrounding muscle tissue for which the IVIM parameters were extracted. Statistical tests were performed in Matlab (2013b, Mathworks, Natick, MA), and a $p$ value of less than 0.001 was considered indicative of a statistically significant difference.

Two-dimensional cross-correlation histograms provide insight in the inter-relationships between parameters [34] and were made for the following combinations: $v_{p} \times$ $K^{\text {trans }}, k_{\mathrm{ep}} \times K^{\text {trans }}, v_{p} \times k_{\mathrm{ep}}, f_{p} \times D_{t}, D_{p} \times D_{t}$, and $f_{p} \times D_{p}$. The same number of bins and ranges were used as for the individual parameter histograms, and the intensities were expressed in percentage of the tumor VOI volume.

To ensure that observed changes in parameter values were induced by hyperthermia, data reproducibility was tested. The IVIM scan of rabbit 1 after hyperthermia was repeated, and the results were compared. Since the DCE scans require the use of a contrast agent, a similar reproducibility test was deemed not feasible for DCE-MRI.

\section{Results}

The T2w MR images acquired during the planning phase showed that all rabbits had one tumor except for rabbit
4, which had three small contiguous tumors. Rabbit 2 had a large necrotic core in the tumor and died during the last few minutes of the hyperthermia treatment.

\section{Tumor VOIs}

In the MR images, it could be observed that all rabbits had one tumor except for rabbit 4, which had three small contiguous tumors. In rabbit 2, a large necrotic core was observed. Table 1 shows the volumes of the tumor VOIs, for which the DCE and IVIM analyses were performed. The discrepancy between the volumes delineated in the DCE and in the IVIM data can be attributed to the differences in the MR images (voxel size, contrast, geometrical distortions by EPI). Note that the volumes before and after hyperthermia were comparable.

\section{MR-HIFU-induced mild hyperthermia}

Three 10-min blocks of mild hyperthermia ( 40 to $42{ }^{\circ} \mathrm{C}$ ) were successfully achieved in all five rabbits using MRHIFU. In rabbit 2, one mild hyperthermia block was manually aborted because of observed motion artifacts in the MR thermometry; in rabbit 4, one mild hyperthermia block was automatically aborted because of connection loss between the MR console and the HIFU console. More details on the mild hyperthermia durations are given in Table 2. Figure 2a, b shows examples of magnitude and temperature images of the MR thermometry sequence; examples of the temporal profiles of $T_{10}, T_{50}$, and $T_{90}$ of the corresponding ROIs (circles) are shown in Fig. 2c. The mean values of $T_{10}, T_{50}$, and $T_{90}$ over the entire hyperthermia duration are shown in Table 3 and plotted in Fig. $2 \mathrm{~d}$ for each rabbit. All $T_{50}$ values were within the desired hyperthermic temperature range of 40 to $42{ }^{\circ} \mathrm{C}$. In the coronal slice of rabbit 3 , the mean $T_{10}$ was higher than $42{ }^{\circ} \mathrm{C}$ and the mean $T_{50}$ was higher than the other rabbits.

\section{Reproducibility}

In Fig. 3, the results of the repeated IVIM scans of rabbit 1, acquired post-hyperthermia, are shown. The parameter maps of the central slice through the tumor (Fig. 3a) look similar, as well as the individual parameter histograms

Table 1 Tumor VOI volume $\left(\mathrm{cm}^{3}\right)$

\begin{tabular}{llllll}
\hline $\begin{array}{lllll}\text { Rabbit } \\
\text { number }\end{array}$ & DCE & & & IVIM & \\
\cline { 2 - 3 } \cline { 5 - 6 } & Pre & Post & & Pre & Post \\
& HT & HT & & HT & HT \\
\hline 1 & 13 & 13 & 19 & 19 \\
2 & 13 & 13 & 20 & 20 \\
3 & 12 & 12 & 17 & 18 \\
4 & 7 & 7 & 13 & 13 \\
5 & 10 & 11 & 17 & 19 \\
\hline
\end{tabular}

HT hyperthermia 
Table 2 Details on MR-HIFU mild hyperthermia of rabbit $V \times 2$ tumors

\begin{tabular}{llllll}
\hline Block & Rabbit 1 & Rabbit 2 & Rabbit 3 & Rabbit 4 & Rabbit 5 \\
\hline HT & $8 \mathrm{~min}$ & $10 \mathrm{~min}$ & $4 \mathrm{~min}$ & $135 \mathrm{~s}^{\mathrm{b}}$ & $10 \mathrm{~min}$ \\
Cool & $5 \mathrm{~min}$ & $5 \mathrm{~min}$ & $8 \mathrm{~min}$ & $13 \mathrm{~min}$ & $11 \mathrm{~min}$ \\
HT & $10 \mathrm{~min}$ & $70 \mathrm{~s}^{\mathrm{a}}$ & $10 \mathrm{~min}$ & $10 \mathrm{~min}$ & $10 \mathrm{~min}$ \\
Cool & $5 \mathrm{~min}$ & $3 \mathrm{~min}$ & $9 \mathrm{~min}$ & $5 \mathrm{~min}$ & $17 \mathrm{~min}$ \\
HT & $10 \mathrm{~min}$ & $10 \mathrm{~min}$ & $10 \mathrm{~min}$ & $10 \mathrm{~min}$ & $10 \mathrm{~min}$ \\
Cool & & $5 \mathrm{~min}$ & & $5 \mathrm{~min}$ & \\
HT & & $10 \mathrm{~min}$ & & $10 \mathrm{~min}$ & \\
Total HT duration & $28 \mathrm{~min}$ & $31 \mathrm{~min}$ & $24 \mathrm{~min}$ & $32 \mathrm{~min}$ & $30 \mathrm{~min}$
\end{tabular}

HT hyperthermia

${ }^{a}$ Manually aborted: motion artifacts in the MR thermometry observed ${ }^{b}$ Automatically aborted: connection loss between the MR console and the HIFU console

(Fig. 3b) and the cross-correlation histograms (Fig. 3c), except for some minor differences in $D_{t}$. Table 4 shows that the median $D_{t}$ values showed a small but statistically significant difference of $0.14 \times 10^{-3} \mathrm{~mm}^{2} / \mathrm{s}(p<0.001)$, while no significant difference was found between the median $f_{p}$ $(p=0.14)$ and $D_{p}$ values $(p=0.09)$.

\section{DCE and IVIM parameter maps}

The DCE and IVIM parameter maps of the central slice through each tumor are displayed in Fig. 4. Please note that the region for which the IVIM analysis was performed is limited to the region included for the Bayesian prior distribution, for which any water from the tank was avoided in the delineation. Variations in the parameter maps can be observed between the rabbits, both before and after hyperthermia. Rabbit 2 died during treatment; the corresponding data were excluded from the analysis. The signal-to-noise ratio of the prehyperthermia IVIM data acquired in rabbit 5 was very low. We therefore decided to refrain from including IVIM data from this animal in any comparisons. Decreased values can be observed in the post-hyperthermia $v_{p}$ map of rabbit $3 \quad\left(v_{p}<0.02\right)$ and in all posthyperthermia DCE maps of rabbit $4\left(v_{p}<0.02, K^{\text {trans }}<\right.$ 0.4 , and $k_{\text {ep }}<0.4$; Fig. 4a).

\section{Histograms and median values}

Pre- and post-hyperthermia histograms of the DCE parameters in the tumor VOIs are shown in Fig. 5a. Variations in the pre-hyperthermia histograms can be observed between the rabbits, in particular, the $k_{\text {ep }}$ histograms. Table 5 shows the comparisons of pre- and posthyperthermia median values of the DCE parameters and the corresponding $p$ values, for both the surrounding muscle and the tumor VOI. In the surrounding muscle, no significant changes were found in the median values of $v_{p}$ in all rabbits and of $k_{\mathrm{ep}}$ in rabbits 1 and 4, while

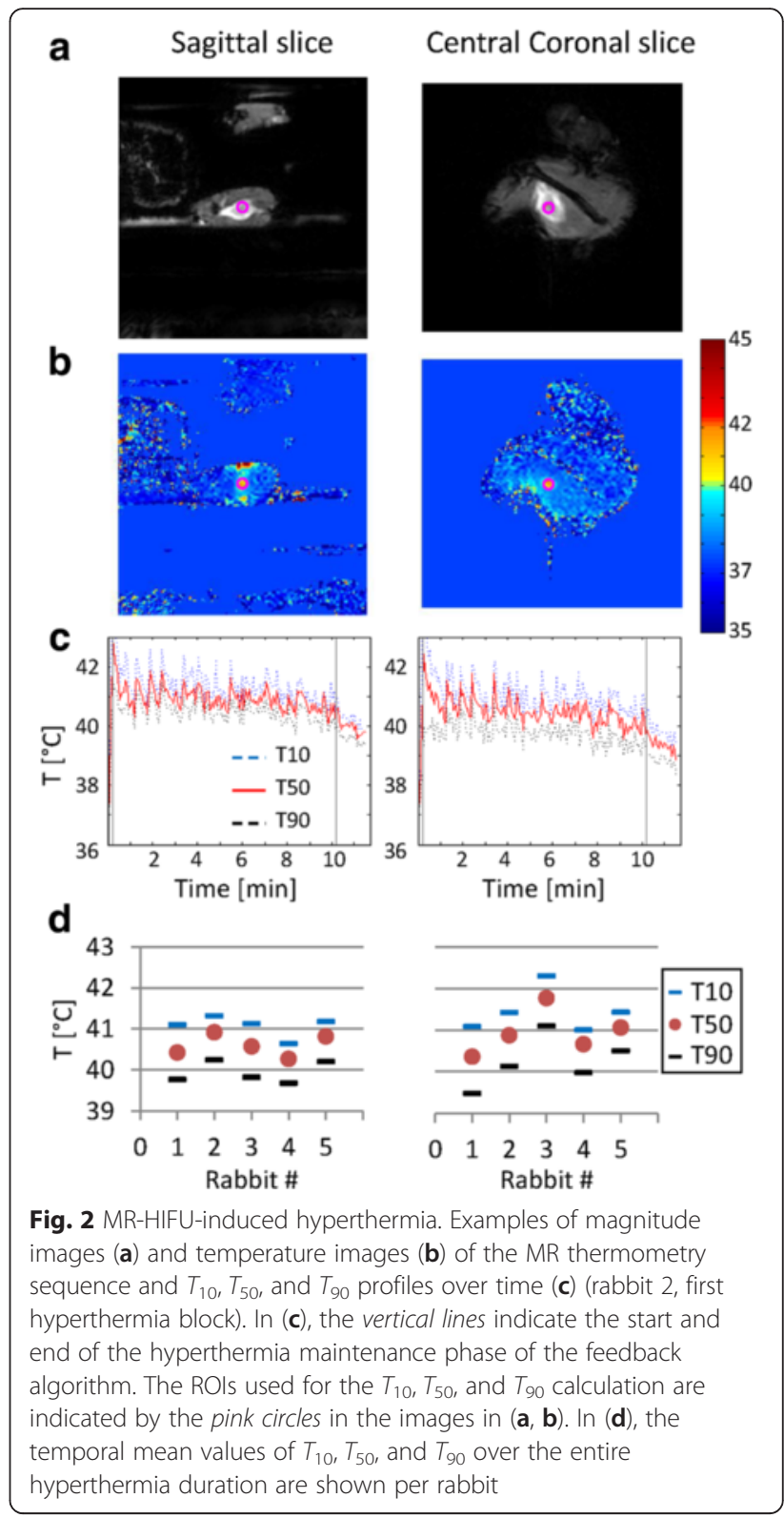

significant increases $(p<0.001)$ were found in the median values of $k_{\text {ep }}$ in rabbits 3 and 5 and of $K^{\text {trans }}$ in all rabbits, in the order of $0.1 \mathrm{~min}^{-1}$. The changes in the tumor VOI are most obvious in rabbit 4, where all three DCE parameter histograms, as well as the median values, shifted towards lower values. For all other rabbits, the $K^{\text {trans }}$ histograms and the median $K^{\text {trans }}$ values shifted towards higher values and the changes in median values were in the order of $0.2 \mathrm{~min}^{-1}$. The median $v_{p}$ increased in rabbits 1 and 5 and decreased in rabbits 3 and 4 . In the $k_{\text {ep }}$ histograms of rabbits 3 and 4 , clear shape changes can be observed. The median $k_{\text {ep }}$ increased in rabbit 1 and decreased in rabbits 4 and 5. In rabbit 3 , the bulk shift in the $k_{\text {ep }}$ distribution towards lower values changed the skewness (Fig. 5a). This 
Table 3 Temporal mean and standard deviation (SD) of $T_{50}, T_{90}$, and $T_{10}$, averaged over the three hyperthermia blocks

\begin{tabular}{|c|c|c|c|c|c|c|}
\hline \multirow[t]{2}{*}{ Rabbit } & \multicolumn{3}{|c|}{ Central coronal slice } & \multicolumn{3}{|c|}{ Sagittal slice } \\
\hline & $T_{50}\left({ }^{\circ} \mathrm{C}\right)$ & $T_{90}\left({ }^{\circ} \mathrm{C}\right)$ & $T_{10}\left({ }^{\circ} \mathrm{C}\right)$ & $T_{50}\left({ }^{\circ} \mathrm{C}\right)$ & $T_{90}\left({ }^{\circ} \mathrm{C}\right)$ & $T_{10}\left({ }^{\circ} \mathrm{C}\right)$ \\
\hline 1 & 40.4 & 39.5 & 41.1 & 40.4 & 39.8 & 41.1 \\
\hline 2 & 40.9 & 40.1 & 41.4 & 40.9 & 40.2 & 41.3 \\
\hline 3 & 41.8 & 41.1 & 42.3 & 40.6 & 39.8 & 41.1 \\
\hline 4 & 40.7 & 40.0 & 41.0 & 40.3 & 39.7 & 40.6 \\
\hline 5 & 41.1 & 40.5 & 41.4 & 40.8 & 40.2 & 41.2 \\
\hline Mean (SD) & $40.9(0.5)$ & $40.2(0.6)$ & $41.4(0.5)$ & $40.6(0.3)$ & $39.9(0.3)$ & $41.1(0.3)$ \\
\hline
\end{tabular}

resulted in an increase in the median $k_{\mathrm{ep}}$ (Table 5), which does not reflect the observed changes in the histogram $(p=0.006)$.

Pre- and post-hyperthermia histograms of the IVIM parameters in the tumor VOIs are shown in Fig. 5b. It is notable that all pre-hyperthermia histograms look different in shape. Table 6 shows the comparisons of the preand post-hyperthermia median values of the IVIM parameters and the corresponding $p$ values, for both the surrounding muscle and the tumor VOI. In the surrounding muscle, no significant changes were found in the median values of $f_{p}$ in all rabbits and of $D_{t}$ in rabbit 1 and of $D_{p}$ in rabbits 3 and 4 . The significant changes in $D_{t}$ in rabbits 3 and 4 were in the order of $0.2 \times 10$ ${ }^{-3} \mathrm{~mm}^{2} / \mathrm{s}$ and in $D_{p}$ in rabbit 1 was $700 \times 10^{-3} \mathrm{~mm}^{2} / \mathrm{s}$. For the tumor VOI, all $D_{t}$ histograms shifted towards higher values after hyperthermia and the changes in the median values in rabbits 3 and 4 were in the order of

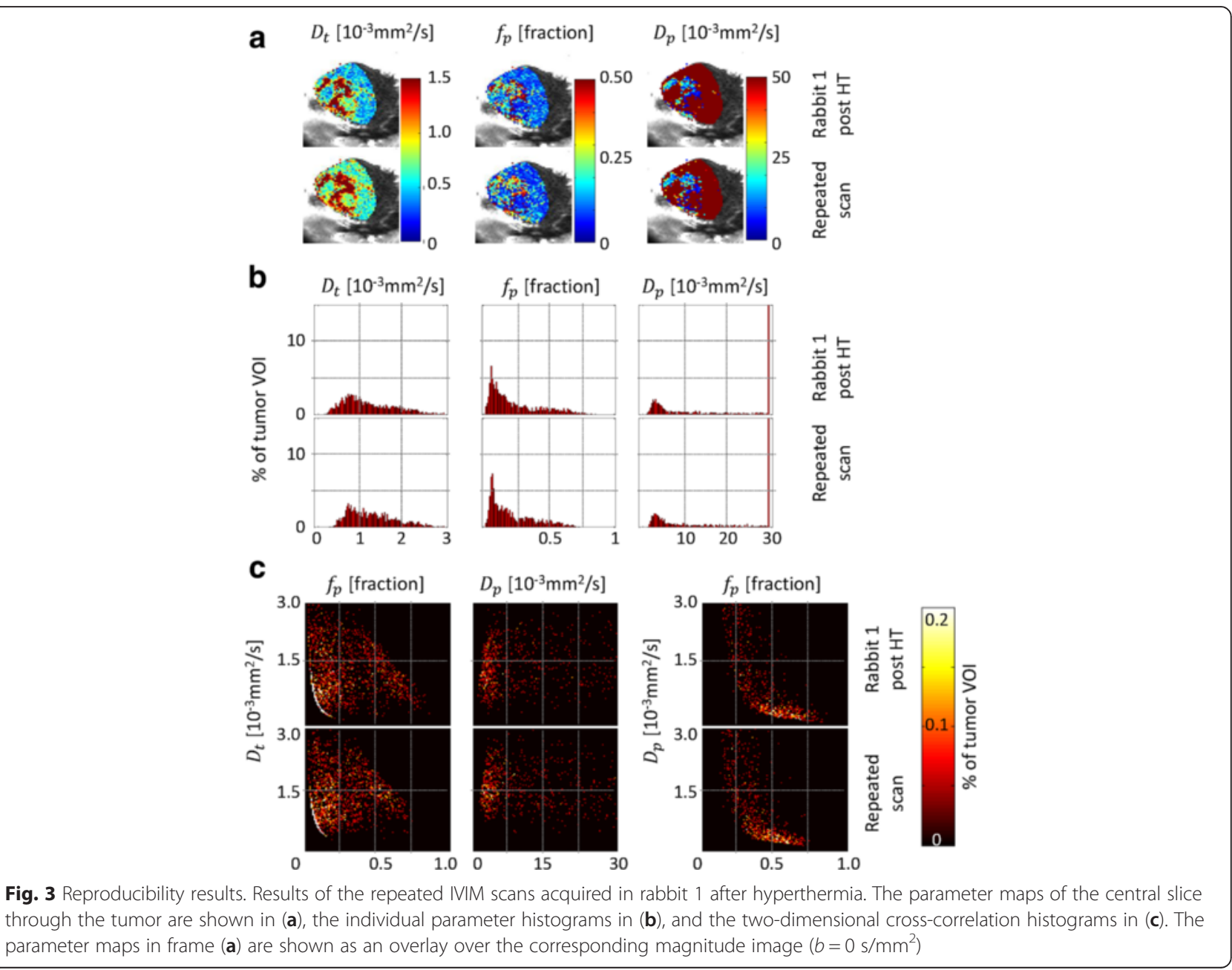


Table 4 Reproducibility test: median IVIM parameter values of two dynamic scans acquired in rabbit 1, post-hyperthermia (HT)

\begin{tabular}{llll}
\hline & Rabbit 1 post-HT & Repeated scan & $p$ value \\
\hline$D_{t}\left[10^{-3} \mathrm{~mm}^{2} / \mathrm{s}\right]$ & 1.06 & 1.20 & $<0.001$ \\
$f_{p}[$ fraction $]$ & 0.16 & 0.17 & 0.14 \\
$D_{p}\left[10^{-3} \mathrm{~mm}^{2} / \mathrm{s}\right]$ & 5.2 & 6.1 & 0.09 \\
\hline
\end{tabular}

$0.4 \times 10^{-3} \mathrm{~mm}^{2} / \mathrm{s}$. In the histograms and median values of $f_{p}$ an increase was found in rabbit 1 and a decrease in rabbits 3 and 4 . The pre-hyperthermia $D_{p}$ histogram of rabbit 1 shows an even distribution covering a wide range, and the median value was much larger than all other median $D_{p}$ values (Table 6). The median $D_{p}$ value decreased in rabbit 3 and increased in rabbit 4.

\section{Cross-correlation histograms}

The two-dimensional cross-correlation histograms of the DCE parameters in the tumor VOIs are displayed in Fig. 6a. The shapes of the different pre-hyperthermia cross-correlation histograms are comparable for rabbits 1, 3, and 5; for rabbit 4, the shapes are less elongated and more diffuse. After hyperthermia, the crosscorrelation histograms of rabbits 1 and 5 become more diffuse, while those of rabbits 3 and 4 become more compact, particularly the $v_{p} \times K^{\text {trans }}$ and $v_{p} \times k_{\text {ep }}$ histograms.

The cross-correlation histograms of the IVIM parameters in the tumor VOIs are displayed in Fig. 6b. In rabbit
1, the pre-hyperthermia $D_{p} \times D_{t}$ histogram shows a strong correlation between the parameters for all voxels, which indicate systematic errors in the parameter estimation. Similarly, the post-hyperthermia $f_{p} \times D_{t}$ histogram of rabbit 1 shows a strong correlation between the parameters for a large portion of the voxels. The crosscorrelation histograms of rabbits 3 and 4 have similar shapes but differ in their distributions: in rabbit 4, there were more voxels with low $f_{p}$ values in combination with high $D_{t}$ values.

\section{Discussion}

DCE-MRI and IVIM-MRI data were acquired before and after MR-HIFU-induced hyperthermia in rabbits with Vx2 tumors. The pre-hyperthermia DCE and IVIM parameter maps and histograms revealed variations between the rabbits. This implies that the group was heterogeneous in terms of DCE and IVIM parameter distributions. This heterogeneity was also observed in five other rabbits that did not receive the hyperthermia treatment and were therefore not included in this study (data not shown). The post-hyperthermia data were acquired within $1 \mathrm{~h}$ after hyperthermia. Although the duration of the physiological effects after applying hyperthermia is a controversial aspect [54], several studies have shown that changes in regional blood flow and permeability persisted and could be detected up to a few hours after hyperthermia [10, 12, 13]. Therefore, it is assumed that the effect of differences in timing of the image

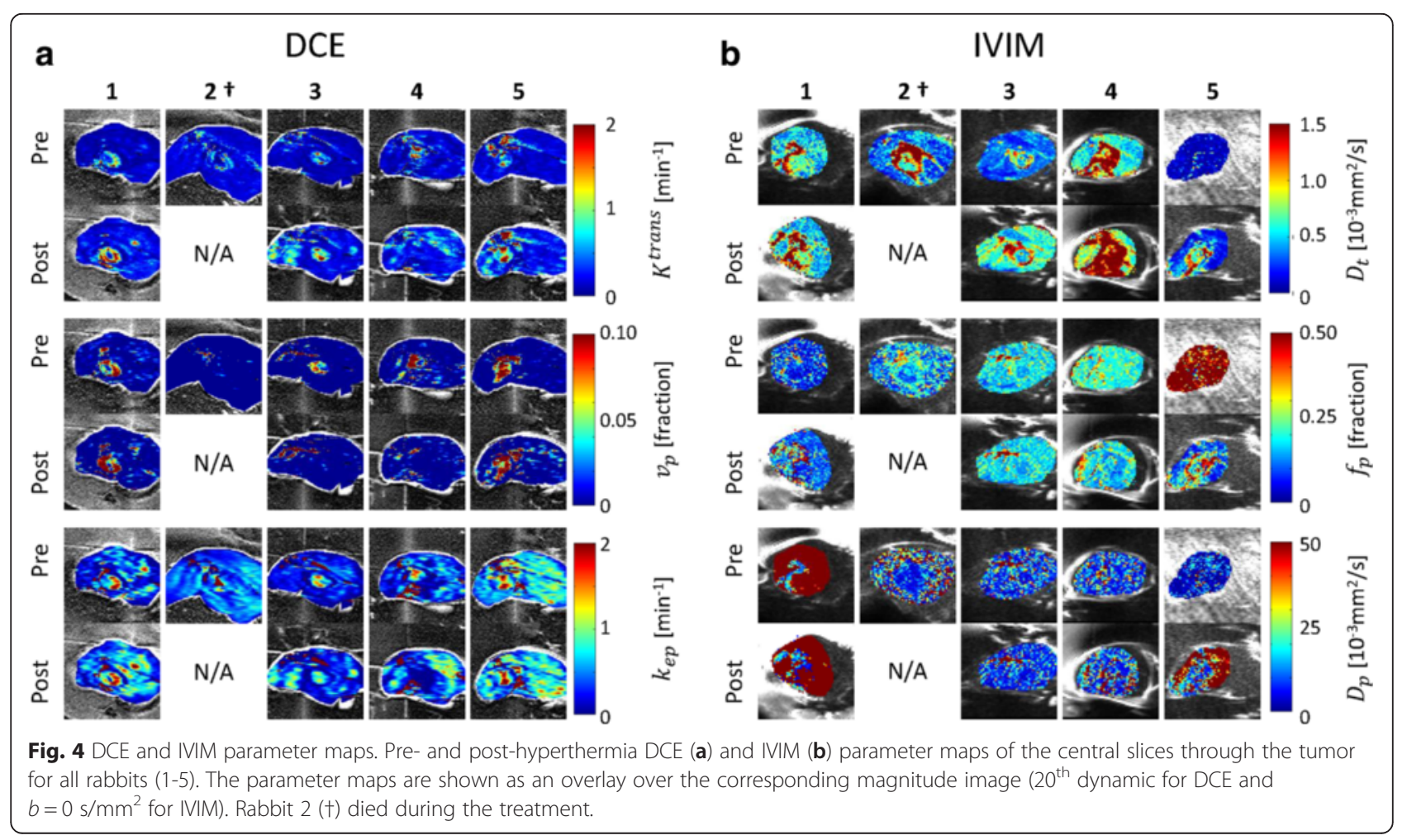






acquisitions on the parameter changes is limited, as compared to other sources. The changes in the DCE and IVIM parameters after hyperthermia varied between the rabbits and are discussed below.

Rabbit 4 had three contiguous small tumors instead of a single tumor and received a few minutes longer hyperthermia than the other rabbits. This combination may have led to a different physiological response in this rabbit as compared to the other rabbits. In the other rabbits (rabbits 1,3 , and 5), increases in $K^{\text {trans }}$ were observed after hyperthermia which were a factor 2 larger than the changes observed in the surrounding muscle. For the median $k_{\text {ep }}$ values, only the change in rabbit 4 could be considered to be significant; the changes in the other rabbits were in the same order as those found in the surrounding muscle. The changes in the median $K^{\text {trans }}$ and $k_{\text {ep }}$ values were in the order of $0.2 \mathrm{~min}^{-1}$, where extreme outliers were excluded to have a realistic representation of the parameter value distribution. Hijnen et al. [38] showed $K^{\text {trans }}$ changes of about $0.1 \mathrm{~min}^{-1}$ after hyperthermia in tumor-bearing mice in the non-necrotic tumor areas, which is in the same order of magnitude as the changes observed in this study. In the whole tumor, changes in the mean $K^{\text {trans }}$ and $k_{\text {ep }}$ values were smaller $\left(0.017\right.$ and $\left.0.022 \mathrm{~min}^{-1}\right)$. Discrepancies between the results may be explained by the different tumor and animal models. In addition, a different model was used for the DCE analysis, standard Tofts 
Table 5 Median DCE parameter values in the surrounding muscle and in the tumor VOI, pre- and post-hyperthermia

\begin{tabular}{|c|c|c|c|c|c|c|c|c|c|c|c|c|}
\hline \multirow{2}{*}{$\begin{array}{l}\text { Surrounding muscle } \\
\text { Rabbit }\end{array}$} & \multicolumn{4}{|c|}{$K^{\text {krans }}\left[\mathrm{min}^{-1}\right]$} & \multicolumn{4}{|c|}{$v_{p}$ [fraction] } & \multicolumn{4}{|c|}{$k_{\mathrm{ep}}\left[\mathrm{min}^{-1}\right]$} \\
\hline & Pre & Post & & $p$ & Pre & Post & & $p$ & Pre & Post & & $p$ \\
\hline 1 & 0.14 & 0.30 & + & $<0.001$ & 0.003 & 0.001 & & 0.077 & 0.65 & 0.74 & & 0.004 \\
\hline 3 & 0.08 & 0.20 & + & $<0.001$ & 0.000 & 0.000 & & 0.021 & 0.26 & 0.37 & + & $<0.001$ \\
\hline 4 & 0.16 & 0.26 & + & $<0.001$ & 0.000 & 0.000 & & 0.476 & 0.43 & 0.48 & & 0.247 \\
\hline 5 & 0.13 & 0.27 & + & $<0.001$ & 0.000 & 0.000 & & 0.817 & 0.81 & 0.96 & + & $<0.001$ \\
\hline Tumor VOI & \multicolumn{4}{|c|}{$K^{\text {trans }}\left[\min ^{-1}\right]$} & \multicolumn{4}{|c|}{$v_{p}[$ fraction $]$} & \multicolumn{4}{|c|}{$k_{\mathrm{ep}}\left[\mathrm{min}^{-1}\right]$} \\
\hline Rabbit & Pre & Post & & $p$ & Pre & Post & & $p$ & Pre & Post & & $p$ \\
\hline 1 & 0.34 & 0.68 & + & $<0.001$ & 0.055 & 0.085 & + & $<0.001$ & 0.68 & 0.80 & + & $<0.001$ \\
\hline 3 & 0.14 & 0.34 & + & $<0.001$ & 0.043 & 0.024 & - & $<0.001$ & 0.36 & 0.41 & & 0.006 \\
\hline 4 & 0.39 & 0.29 & - & $<0.001$ & 0.053 & 0.030 & - & $<0.001$ & 0.57 & 0.26 & - & $<0.001$ \\
\hline 5 & 0.30 & 0.47 & + & $<0.001$ & 0.087 & 0.110 & + & $<0.001$ & 0.74 & 0.62 & - & $<0.001$ \\
\hline
\end{tabular}

Plus signs (+) indicate significant increase after hyperthermia, and minus signs (-) indicate significant decrease after hyperthermia

[55] versus extended Tofts [18], resulting in a discrepancy in the permeability and flow contributions in $K^{\text {trans }}[56]$.

The changes in $v_{p}$ with $(p<0.001)$ in the tumor VOI can be considered to be significant, as no significant changes were observed in the surrounding muscle. An increase in $v_{p}$ was observed in rabbits 1 and 5 and a decrease in rabbit 3. Interestingly, hyperthermic temperatures measured in the coronal slice of rabbit 3 were higher than in the other rabbits: the mean $T_{50}$ was close to $42{ }^{\circ} \mathrm{C}$ and the mean $T_{10}$ was higher than $42{ }^{\circ} \mathrm{C}$. Since $v_{p}$ represents the blood plasma volume fraction in a voxel, it is strongly related to the size of the vessels. It is well known that tumor capillaries are hastily formed and lack the ability to actively dilate. However, tumor capillaries may passively dilate upon hyperthermia, as a result of increased blood flow in adjacent tissue or of increased cardiac output [7], which may explain the increase in $v_{p}$ observed in rabbits 1 and 5. At moderate hyperthermic temperatures $\left(>42{ }^{\circ} \mathrm{C}\right)$, reduced tumor vessel diameters have been reported in Vx2 tumors in rabbit ear chambers [8], which may explain the observed $v_{p}$ decrease in rabbit 3.
Dudar and Jain [8] suggested that the reduction of tumor vessel diameters may be attributed to swelling of the endothelial cells and tissue parenchyma, induced by a decreased $\mathrm{pH}$ in tumors during hyperthermia. The $k_{\mathrm{ep}}$ histogram shapes of rabbits 3 and 4 clearly changed after hyperthermia to a more compact distribution. It is notable that these are the same rabbits that showed a decrease in $v_{p}$. This potential relation can be seen more clearly in the $v_{p} \times k_{\mathrm{ep}}$ histograms of these rabbits.

For the IVIM analysis, the reproducibility was tested by comparing a repeated IVIM scan. No significant differences were found between the $f_{p}$ and $D_{p}$ histograms and median values $(p=0.14$ and $p=0.09)$; the changes in $D_{t}$ were significantly different and relatively small compared to the median values (13 and $12 \%$ ).

The pre-hyperthermia IVIM data of rabbit 5 had a low signal-to-noise ratio, possibly due to motion during the acquisition; hence, a reliable comparison with the posthyperthermia data was not possible. A clear increase in $D_{t}$ after hyperthermia could be seen in rabbits 1,3 , and 4 . The changes in the median values were factors of $1.7,2.6$, and

Table 6 Median IVIM parameter values in surrounding muscle and in the tumor VOI, pre- and post-hyperthermia

\begin{tabular}{|c|c|c|c|c|c|c|c|c|c|c|c|c|}
\hline Surrounding muscle & \multicolumn{4}{|c|}{$D_{t}\left[10^{-3} \mathrm{~mm}^{2} / \mathrm{s}\right]$} & \multicolumn{4}{|c|}{$f_{p}[$ fraction $]$} & \multicolumn{4}{|c|}{$D_{p}\left[10^{-3} \mathrm{~mm}^{2} / \mathrm{s}\right]$} \\
\hline Rabbit & Pre & Post & & $p$ & Pre & Post & & $p$ & Pre & Post & & $p$ \\
\hline 1 & 0.42 & 0.46 & & 0.670 & 0.07 & 0.10 & & 0.026 & 300 & 1000 & + & $<0.001$ \\
\hline 3 & 0.32 & 0.60 & + & $<0.001$ & 0.16 & 0.18 & & 0.642 & 5.6 & 5.4 & & 0.509 \\
\hline 4 & 0.46 & 0.55 & - & $<0.001$ & 0.18 & 0.16 & & 0.060 & 6.6 & 8.2 & & 0.497 \\
\hline Tumor VOI & \multicolumn{4}{|c|}{$D_{t}\left[10^{-3} \mathrm{~mm}^{2} / \mathrm{s}\right]$} & \multicolumn{4}{|c|}{$f_{p}[$ fraction $]$} & \multicolumn{4}{|c|}{$D_{p}\left[10^{-3} \mathrm{~mm}^{2} / \mathrm{s}\right]$} \\
\hline Rabbit & Pre & Post & & $p$ & Pre & Post & & $p$ & Pre & Post & & $p$ \\
\hline 1 & 0.82 & 1.06 & + & $<0.001$ & 0.10 & 0.16 & + & $<0.001$ & 13.5 & 5.2 & - & $<0.001$ \\
\hline 3 & 0.40 & 0.76 & + & $<0.001$ & 0.19 & 0.17 & - & $<0.001$ & 7.6 & 5.0 & - & $<0.001$ \\
\hline 4 & 1.40 & 1.82 & + & $<0.001$ & 0.20 & 0.16 & - & $<0.001$ & 4.7 & 6.0 & + & $<0.001$ \\
\hline
\end{tabular}

Plus signs (+) indicate significant increase after hyperthermia, and minus signs (-) indicate significant decrease after hyperthermia 


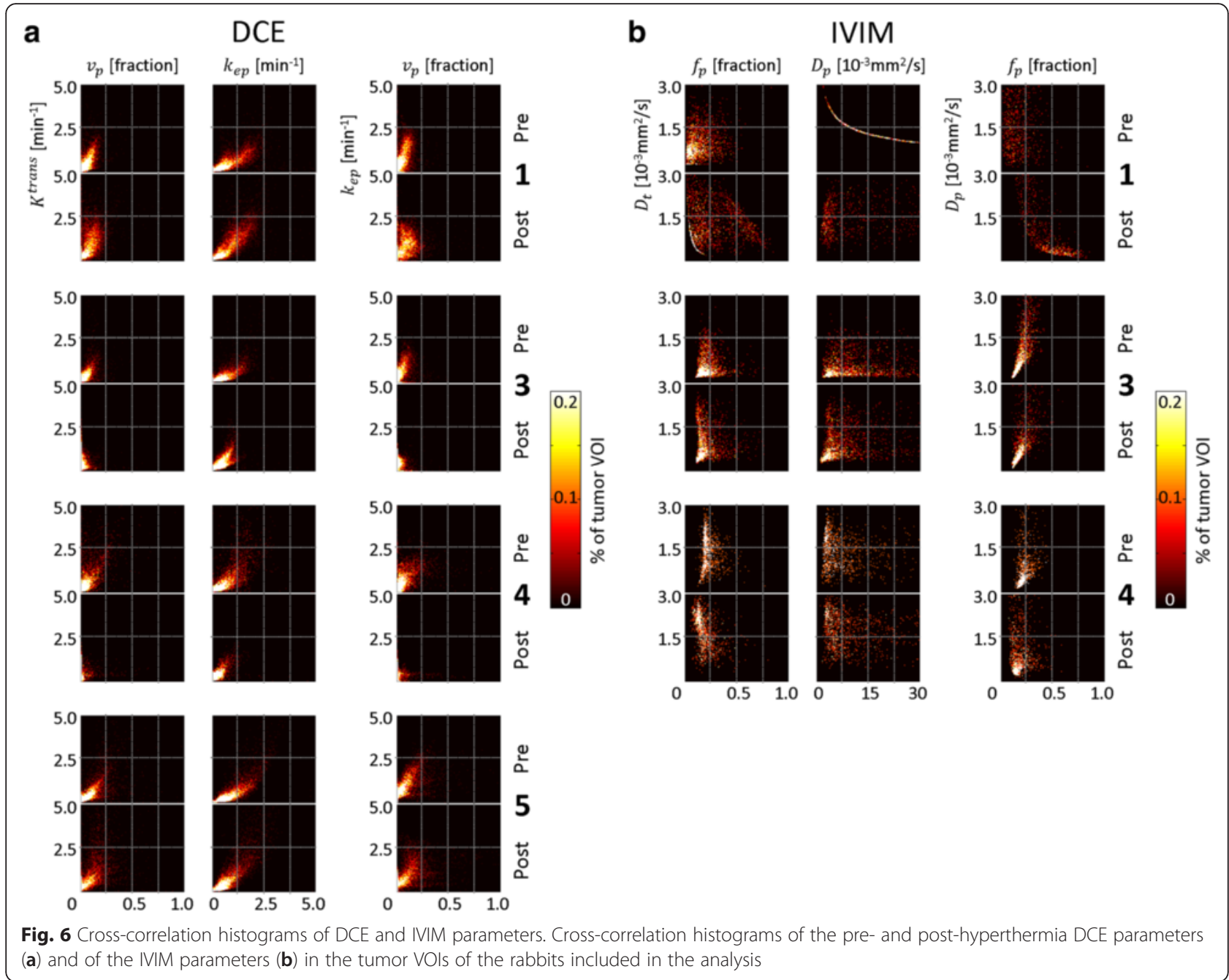

3.0 times larger than the changes found in the reproducibility test and factors of $6,1.3$, and 4.7 times larger than the changes found in the surrounding muscle. This indicates that the observed changes in $D_{t}$ are likely to be induced by hyperthermia. For $f_{p}$, no significant changes were found in the surrounding muscle. In the tumor VOI, an increase in $f_{p}$ was observed in rabbit 1 and a decrease in rabbits 3 and 4 , similar to the changes observed in $v_{p}$. While the interpretations of $f_{p}$ and $v_{p}$ are different, signal fraction and volume fraction, respectively, the parameters are strongly related to each other as they both reflect the intra-voxel fraction of the vascular component.

The $f_{p}$ values in rabbit 1 are much lower than in the other rabbits, which indicate an overall small contribution of vascular components to the signal. The cross-correlation histograms of these data revealed a strong correlation between $D_{t}$ and $D_{p}$, suggesting systematic errors in the parameter estimation. The low $f_{p}$ values are likely the reason for the systematic $D_{p}$ estimation errors, inasmuch $D_{p}$ cannot be estimated accurately when $f_{p}$ is too low $[57,58]$.
While the results show that changes in DCE and IVIM parameters after MR-HIFU-induced hyperthermia could be detected, the changes were found to be variable between the rabbits. The group appeared to be heterogeneous in terms of DCE and IVIM parameter distributions, and it is likely that such a start condition would result in a heterogeneous outcome. In future research, stratification of starting conditions would be desirable, which requires a larger number of subjects.

\section{Conclusions}

In this study, we have shown that DCE and IVIM parameters maps and (cross-correlation) histograms could be constructed to detect changes after MR-HIFUinduced hyperthermia in rabbit Vx2 tumors. Perfusion parameter histograms provided insight into the changes of the parameter distributions and showed that changes in most of the median values were statistically significant $(p<0.001)$. However, the detected changes were variable between the rabbits. The results suggest that DCE- and 
IVIM-MRI may be promising tools to assess tumor physiology responses to hyperthermia. Further research in a larger number of subjects is necessary to assess their value for treatment response monitoring.

\section{Competing interests}

The authors declare that they have no competing interests.

\section{Authors' contributions}

ML participated in the design of the current study, participated in the experiments, performed the DCE data analysis and comparison analysis, and drafted the manuscript. $C O$ and $A B$ participated in the experiments. MF performed the IVIM data analysis. RD, MV, and CM drafted the manuscript. CB participated in the design of the study, participated in the experiments, supervised the data analysis, and drafted the manuscript. LB participated in the design of the study, supervised the data analysis, and drafted the manuscript. All authors read and approved the final manuscript.

\section{Acknowledgements}

The authors are indebted to thank Nico J. M. Attevelt and his colleagues from the Faculty of Veterinary Medicine, Utrecht University, for their support in the animal handling. This research was performed within the framework of CTMM, the Center for Translational Molecular Medicine (www.ctmm.nl), project HIFU-CHEM (grant 030-301).

\section{Received: 28 July 2015 Accepted: 29 February 2016}

Published online: 15 March 2016

\section{References}

1. Overgaard J, Gonzalez Gonzalez D, Hulshof MC, Arcangeli G, Dahl O, Mella $\mathrm{O}$, et al. Randomised trial of hyperthermia as adjuvant to radiotherapy for recurrent or metastatic malignant melanoma. European Society for Hyperthermic Oncology. Lancet. 1995;345(8949):540-3.

2. Falk MH, Issels RD. Hyperthermia in oncology. Int J Hyperthermia. 2001;17(1):1-18.

3. Grull $H$, Langereis $S$. Hyperthermia-triggered drug delivery from temperaturesensitive liposomes using MRl-guided high intensity focused ultrasound. J Control Release. 2012;161(2):317-27. doi:10.1016/j.jconrel.2012.04.041.

4. McDaniel JR, Dewhirst MW, Chilkoti A. Actively targeting solid tumours with thermoresponsive drug delivery systems that respond to mild hyperthermia. Int J Hyperthermia. 2013;29(6):501-10. doi:10.3109/02656736.2013.819999.

5. Jain RK. Haemodynamic and transport barriers to the treatment of solid tumours. Int J Radiat Biol. 1991:60(1-2):85-100.

6. Li SP, Padhani AR. Tumor response assessments with diffusion and perfusion MRI. J Magn Reson Imaging. 2012;35(4):745-63. doi:10.1002/jmri.22838.

7. Song CW. Effect of local hyperthermia on blood flow and microenvironment: a review. Cancer Res. 1984;44(10 Suppl):4721s-30s.

8. Dudar TE, Jain RK. Differential response of normal and tumor microcirculation to hyperthermia. Cancer Res. 1984;44(2):605-12.

9. Gerlowski LE, Jain RK. Effect of hyperthermia on microvascular permeability to macromolecules in normal and tumor tissues. Int J Microcirc Clin Exp. 1985;4(4):363-72.

10. Matsuda $H$, Sugimachi K, Kuwano H, Mori M. Hyperthermia, tissue microcirculation, and temporarily increased thermosensitivity in VX2 carcinoma in rabbit liver. Cancer Res. 1989;49(10):2777-82.

11. Gnant MF, Noll LA, Terrill RE, Wu PC, Berger AC, Nguyen HQ, et al. Isolated hepatic perfusion for lapine liver metastases: impact of hyperthermia on permeability of tumor neovasculature. Surgery. 1999;126(5):890-9.

12. Kong G, Braun RD, Dewhirst MW. Characterization of the effect of hyperthermia on nanoparticle extravasation from tumor vasculature. Cancer Res. 2001;61(7):3027-32.

13. Li L, ten Hagen TLM, Bolkestein M, Gasselhuber A, Yatvin J, van Rhoon GC, et al. Improved intratumoral nanoparticle extravasation and penetration by mild hyperthermia. J Control Release. 2013;167(2):130-7. doi:10.1016/j.jconrel.2013.01.026.

14. Craciunescu OI, Thrall DE, Vujaskovic Z, Dewhirst MW. Magnetic resonance imaging: a potential tool in assessing the addition of hyperthermia to neoadjuvant therapy in patients with locally advanced breast cancer. Int J Hyperthermia. 2010;26(7):625-37. doi:10.3109/02656736.2010.499526.
15. Ludemann L, Wust P, Gellermann J. Perfusion measurement using DCE-MRI: implications for hyperthermia. Int J Hyperthermia. 2008;24(1):91-6. doi:10.1080/02656730701836954.

16. Tofts PS, Berkowitz B, Schnall MD. Quantitative analysis of dynamic Gd-DTPA enhancement in breast tumors using a permeability model. Magn Reson Med. 1995;33(4):564-8.

17. Sourbron SP, Buckley DL. Tracer kinetic modelling in MRI: estimating perfusion and capillary permeability. Phys Med Biol. 2012;57(2):R1-33. doi:10.1088/0031-9155/57/2/r1

18. Tofts PS. Modeling tracer kinetics in dynamic Gd-DTPA MR imaging. J Magn Reson Imaging. 1997;7(1):91-101.

19. Tofts PS, Brix G, Buckley DL, Evelhoch JL, Henderson E, Knopp MV, et al. Estimating kinetic parameters from dynamic contrast-enhanced T(1)weighted MRI of a diffusable tracer: standardized quantities and symbols. J Magn Reson Imaging. 1999;10(3):223-32.

20. Zahra MA, Hollingsworth KG, Sala E, Lomas DJ, Tan LT. Dynamic contrastenhanced MRI as a predictor of tumour response to radiotherapy. Lancet Oncol. 2007;8(1):63-74. doi:10.1016/s1470-2045(06)71012-9.

21. Larsen VA, Simonsen HJ, Law I, Larsson HB, Hansen AE. Evaluation of dynamic contrast-enhanced T1-weighted perfusion MRI in the differentiation of tumor recurrence from radiation necrosis. Neuroradiology. 2013;55(3):361-9. doi:10.1007/s00234-012-1127-4

22. Li SP, Makris A, Beresford MJ, Taylor NJ, Ah-See ML, Stirling JJ, et al. Use of dynamic contrast-enhanced MR imaging to predict survival in patients with primary breast cancer undergoing neoadjuvant chemotherapy. Radiology. 2011;260(1):68-78. doi:10.1148/radiol.11102493.

23. Cho N, Im SA, Park IA, Lee KH, Li M, Han W, et al. Breast cancer: early prediction of response to neoadjuvant chemotherapy using parametric response maps for MR imaging. Radiology. 2014;272(2):385-96. doi:10.1148/radiol.14131332.

24. Li X, Arlinghaus LR, Ayers GD, Chakravarthy AB, Abramson RG, Abramson $V G$, et al. DCE-MRI analysis methods for predicting the response of breast cancer to neoadjuvant chemotherapy: pilot study findings. Magn Reson Med. 2014;71(4):1592-602. doi:10.1002/mrm.24782.

25. Intven M, Reerink O, Philippens ME. Dynamic contrast enhanced MR imaging for rectal cancer response assessment after neo-adjuvant chemoradiation. J Magn Reson Imaging. 2014. doi:10.1002/jmri.24718.

26. Zheng $D$, Chen Y, Liu X, Chen Y, Xu L, Ren W, et al. Early response to chemoradiotherapy for nasopharyngeal carcinoma treatment: value of dynamic contrast-enhanced 3.0 T MRI. J Magn Reson Imaging. 2014. doi:10.1002/jmri.24723.

27. Park JJ, Kim CK, Park SY, Simonetti AW, Kim E, Park BK, et al. Assessment of early response to concurrent chemoradiotherapy in cervical cancer: value of diffusion-weighted and dynamic contrast-enhanced MR imaging. Magn Reson Imaging. 2014;32(8):993-1000. doi:10.1016/j.mri.2014.05.009.

28. Le Bihan D, Breton E, Lallemand D, Aubin ML, Vignaud J, Laval-Jeantet M. Separation of diffusion and perfusion in intravoxel incoherent motion MR imaging. Radiology. 1988;168(2):497-505. doi:10.1148/radiology.168.2.3393671.

29. Henkelman RM. Does IVIM measure classical perfusion? Magn Reson Med. 1990;16(3):470-5.

30. Le Bihan D, Turner R. The capillary network: a link between IVIM and classical perfusion. Magn Reson Med. 1992;27(1):171-8.

31. Lemke A, Laun FB, Simon D, Stieltjes B, Schad LR. An in vivo verification of the intravoxel incoherent motion effect in diffusion-weighted imaging of the abdomen. Magn Reson Med. 2010;64(6):1580-5. doi:10.1002/mrm.22565.

32. Luciani A, Vignaud A, Cavet M, Nhieu JT, Mallat A, Ruel L, et al. Liver cirrhosis: intravoxel incoherent motion MR imaging-pilot study. Radiology. 2008;249(3):891-9. doi:10.1148/radiol.2493080080.

33. Lemke A, Laun FB, Klauss M, Re TJ, Simon D, Delorme S, et al. Differentiation of pancreas carcinoma from healthy pancreatic tissue using multiple bvalues: comparison of apparent diffusion coefficient and intravoxel incoherent motion derived parameters. Invest Radiol. 2009;44(12):769-75. doi:10.1097/RLI.0b013e3181b62271.

34. Sigmund EE, Cho GY, Kim S, Finn M, Moccaldi M, Jensen JH, et al. Intravoxel incoherent motion imaging of tumor microenvironment in locally advanced breast cancer. Magn Reson Med. 2011;65(5):1437-47. doi:10.1002/mrm.22740.

35. Sumi M, Van Cauteren M, Sumi T, Obara M, Ichikawa Y, Nakamura T. Salivary gland tumors: use of intravoxel incoherent motion MR imaging for assessment of diffusion and perfusion for the differentiation of benign from malignant tumors. Radiology. 2012;263(3):770-7. doi:10.1148/radiol. 12111248. 
36. Federau C, O'Brien K, Meuli R, Hagmann P, Maeder P. Measuring brain perfusion with intravoxel incoherent motion (IVIM): initial clinical experience. J Magn Reson Imaging. 2014;39(3):624-32. doi:10.1002/jmri.24195.

37. Gaing B, Sigmund EE, Huang WC, Babb JS, Parikh NS, Stoffel D, et al. Subtype differentiation of renal tumors using voxel-based histogram analysis of intravoxel incoherent motion parameters. Invest Radiol. 2015; 50(3):144-52. doi:10.1097/rli.0000000000000111.

38. Hijnen NM, Heijman E, Kohler MO, Ylihautala M, Ehnholm GJ, Simonetti AW, et al. Tumour hyperthermia and ablation in rats using a clinical MR-HIFU system equipped with a dedicated small animal set-up. Int J Hyperthermia. 2012;28(2):141-55. doi:10.3109/02656736.2011.648137.

39. Staruch R, Chopra R, Hynynen K. Hyperthermia in bone generated with MR imaging-controlled focused ultrasound: control strategies and drug delivery. Radiology. 2012;263(1):117-27. doi:10.1148/radiol.12111189.

40. Ranjan A, Jacobs GC, Woods DL, Negussie AH, Partanen A, Yarmolenko PS, et al. Image-guided drug delivery with magnetic resonance guided high intensity focused ultrasound and temperature sensitive liposomes in a rabbit Vx2 tumor model. J Control Release. 2012;158(3):487-94. doi:10.1016/j. jconrel.2011.12.011.

41. de Smet M, Hijnen NM, Langereis S, Elevelt A, Heijman E, Dubois L, et al. Magnetic resonance guided high-intensity focused ultrasound mediated hyperthermia improves the intratumoral distribution of temperaturesensitive liposomal doxorubicin. Invest Radiol. 2013;48(6):395-405. doi:10.1097/RLI.0b013e3182806940.

42. Staruch RM, Hynynen K, Chopra R. Hyperthermia-mediated doxorubicin release from thermosensitive liposomes using MR-HIFU: therapeutic effect in rabbit Vx2 tumours. Int J Hyperthermia. 2015;31(2):118-33. doi:10.3109/ 02656736.2014 .992483

43. Wijlemans JW, Deckers $R$, van den Bosch MA, Seinstra BA, van Stralen M, van Diest PJ, et al. Evolution of the ablation region after magnetic resonance-guided high-intensity focused ultrasound ablation in a Vx2 tumor model. Invest Radiol. 2013;48(6):381-6. doi:10.1097/RLI. Ob013e3182820257.

44. De Poorter J, De Wagter C, De Deene Y, Thomsen C, Ståhlberg F, Achten E. Noninvasive MRI thermometry with the proton resonance frequency (PRF) method: in vivo results in human muscle. Magn Reson Med. 1995;33:74-81.

45. Ishihara Y, Calderon A, Watanabe H, Okamoto K, Suzuki Y, Kuroda K, et al. A precise and fast temperature mapping using water proton chemical shift. Magn Reson Med. 1995;34:814-23.

46. Vijayakumar S, Huang F, RD E. Improved partial k-space reconstruction technique for dynamic myocardial perfusion MRI. Conf Proc IEEE Eng Med Biol Soc. 2005;2:1419-21. doi:10.1109/iembs.2005.1616696.

47. Kohler MO, Mougenot C, Quesson B, Enholm J, Le Bail B, Laurent C, et al. Volumetric HIFU ablation under 3D guidance of rapid MRI thermometry. Med Phys. 2009;36(8):3521-35.

48. Partanen A, Yarmolenko PS, Viitala A, Appanaboyina S, Haemmerich D, Ranjan A, et al. Mild hyperthermia with magnetic resonance-guided highintensity focused ultrasound for applications in drug delivery. Int J Hyperthermia. 2012;28(4):320-36. doi:10.3109/02656736.2012.680173.

49. Haacke EM, Filleti CL, Gattu R, Ciulla C, Al-Bashir A, Suryanarayanan K, et al. New algorithm for quantifying vascular changes in dynamic contrastenhanced MRI independent of absolute T1 values. Magn Reson Med. 2007;58(3):463-72. doi:10.1002/mrm.21358.

50. Thompson Jr HK, Starmer CF, Whalen RE, McIntosh HD. Indicator transit time considered as a gamma variate. Circ Res. 1964;14:502-15.

51. O'Neill BE, Vo HQ, Shao H, Karmonik C, Zhou X, Li KC. MRI-based prediction of pulsed high-intensity focused ultrasound effect on tissue transport in rabbit muscle. J Magn Reson Imaging. 2013;38(5):1094-102. doi:10.1002/jmri.24087.

52. Orton MR, Collins DJ, Koh DM, Leach MO. Improved intravoxel incoherent motion analysis of diffusion weighted imaging by data driven Bayesian modeling. Magn Reson Med. 2014;71(1):411-20. doi:10.1002/mrm.24649.

53. Zhang YD, Wang Q, Wu CJ, Wang XN, Zhang J, Liu H, et al. The histogram analysis of diffusion-weighted intravoxel incoherent motion (IVIM) imaging for differentiating the Gleason grade of prostate cancer. Eur Radiol. 2015; 25(4):994-1004. doi:10.1007/s00330-014-3511-4.

54. Horsman MR. Tissue physiology and the response to heat. Int J Hyperthermia. 2006;22(3):197-203. doi:10.1080/02656730600689066.

55. Tofts PS, Kermode AG. Measurement of the blood-brain barrier permeability and leakage space using dynamic MR imaging. 1. Fundamental concepts. Magn Reson Med. 1991;17(2):357-67.
56. Sourbron SP, Buckley DL. On the scope and interpretation of the Tofts models for DCE-MRI. Magn Reson Med. 2011;66(3):735-45. doi:10.1002/mrm.22861.

57. Pekar J, Moonen CTW, van Zijl PCM. On the precision of diffusion/perfusion imaging by gradient sensitization. Magn Reson Med. 1992;23(1):122-9. doi:10.1002/mrm.1910230113.

58. Lam MK, Bos C, Moonen CTW, Viergever MA, Bartels LW. Precision and accuracy of intravoxel incoherent motion (IVIM) MRI: applicability in wellperfused tissues. Milan: International Society for Magnetic Resonance in Medicine; 2014.

\section{Submit your next manuscript to BioMed Central and we will help you at every step:}

- We accept pre-submission inquiries

- Our selector tool helps you to find the most relevant journal

- We provide round the clock customer support

- Convenient online submission

- Thorough peer review

- Inclusion in PubMed and all major indexing services

- Maximum visibility for your research

Submit your manuscript at www.biomedcentral.com/submit
C Biomed Central 